\title{
Differential Impact of an Eclipse on Photosynthetic Performance of Trees with Different Degrees of Shade Tolerance
}

\author{
Marco A. Molina-Montenegro ${ }^{1,2,3, * \mathbb{D}}$, Cristian Atala ${ }^{4}(\mathbb{D})$ and Fernando Carrasco-Urra ${ }^{1}$ \\ 1 Instituto de Ciencias Biológicas, Universidad de Talca, Campus Lircay, Talca 3460000, Chile; \\ fernando.carrasco@utalca.cl \\ 2 Centro de Estudios Avanzados en Zonas Áridas (CEAZA), Facultad de Ciencias del Mar, \\ Universidad Católica del Norte, Coquimbo 1780000, Chile \\ 3 Centro de Investigación de Estudios Avanzados del Maule (CIEAM), Universidad Católica del Maule, \\ Talca 3460000, Chile \\ 4 Facultad de Ciencias, Instituto de Biología, Pontificia Universidad Católica de Valparaíso, Curauma, \\ Valparaíso 2340000, Chile; cristian.atala@pucv.cl \\ * Correspondence: marco.molina@utalca.cl
}

check for updates

Citation: Molina-Montenegro, M.A.; Atala, C.; Carrasco-Urra, F.

Differential Impact of an Eclipse on Photosynthetic Performance of Trees with Different Degrees of Shade Tolerance. Forests 2021, 12, 1353. https://doi.org/10.3390/f12101353

Academic Editor: Francois Girard

Received: 14 August 2021

Accepted: 28 September 2021

Published: 4 October 2021

Publisher's Note: MDPI stays neutral with regard to jurisdictional claims in published maps and institutional affiliations.

Copyright: (c) 2021 by the authors. Licensee MDPI, Basel, Switzerland. This article is an open access article distributed under the terms and conditions of the Creative Commons Attribution (CC BY) license (https:// creativecommons.org/licenses/by/ $4.0 /)$.

\begin{abstract}
Solar eclipses represent a natural and unexpected event for plants that can potentially affect photosynthetic performance at the individual level. This effect, however, has seldom been evaluated. Here, we measured the impact of a total solar eclipse on the photosynthetic rate of different tree species-located in the Bosque Fray Jorge National Park, Chile-with varying degrees of shade tolerance. Specifically, we assessed whether the rapid and progressive light limitation facilitated by a solar eclipse would negatively impact the photosynthetic responses of these tree species and whether their photosynthetic performance would have a greater decrease when the percentage of eclipse shadow was higher, particularly in the less shade-tolerant species. To accomplish this, we compared daily changes in the photosynthetic rates of three tree species during a control (non-eclipse) vs. an eclipse day that occurred on 2 July 2019. Overall, tree species showed differences between a non-eclipse and eclipse day in the daily dynamics of their photosynthetic performance, with this trend being most evident at the peak of the solar eclipse. Additionally, each species showed a different pattern of de-epoxidation in accordance with its degree of shade tolerance. Our results suggest that solar eclipses negatively affect the photosynthesis of the studied Chilean tree species, which may be related to energy dissipation capacity via the de-epoxidation of xanthophyll pigments. This effect was more evident in shade-intolerant species, indicating that eclipses can present different consequences for the overall performance of various plant species.
\end{abstract}

Keywords: xanthophyll cycle; photosynthesis; shade tolerance

\section{Introduction}

A solar eclipse is an astronomical event that occurs when the Moon is located between the Earth and the Sun. During an eclipse, the Moon blocks the Sun's light from reaching a part of the Earth, which is, thus, obscured by the Moon's shadow. The eclipse can be partial or total, depending on the degree of superposition of the Sun and Moon. Studies on animal behavior during solar eclipses have shown various responses to this astronomical event around the Earth [1,2]. For example, considering different bird species on the north coast of Venezuela, a decrease in flight behavior has been observed associated with the reduced solar light during an eclipse [1]. On the other hand, a study on bees showed that decreased temperature had an impact on their activity, and most variations in buzzing rate were attributable to changes in light intensities during an eclipse [3].

Fewer studies, however, have assessed plants' responses to eclipses. Variations in temperature and incoming radiation are considered primary drivers of photosynthetic processes and, in turn, carbon balance [4]. A recent study showed that rapid changes 
in sunlight and air temperature during a total solar eclipse on 21 August 2017, in the USA negatively impacted photosynthesis in Artemisia tridentata [5]. Furthermore, solar eclipses represent natural and unexpected events for plants [5] that can potentially affect photosynthetic performance at the individual level. In fact, an eclipse could be considered a natural experiment for brief alterations in environmental factors (mainly light and temperature), with likely consequences for photosynthesis. However, this effect has seldom been experimentally evaluated. This is likely due, at least in part, to the rarity of occurrence of total eclipses in any given part of the world.

The Chilean territory stretches $4337 \mathrm{~km}$ along the south-western margin of South America (from $17^{\circ}$ to $56^{\circ} \mathrm{S}$ ). On this territory, abiotic factors vary, influencing the distribution of plant species that inhabit native Chilean forests. The variation in light conditions under these canopies has great importance in the growth and survival of plants, where the shade tolerance and the minimum light requirement for plant survival are crucial traits for understanding forest dynamics [6,7]. At the physiological level, plants must maintain chlorophyll's function and convert sunlight into chemical energy [8]; however, if photochemical capacity is exceeded by incoming energy, plants can generate photoprotective mechanisms to avoid photoinhibition [9]. These mechanisms involve a group of pigments known as xanthophylls (violaxanthin, V; antheraxanthin, A; zeaxanthin, Z), which form the xanthophyll cycle. Their de-epoxidation level, calculated as the $(0.5 \times \mathrm{A}+\mathrm{Z}) /(\mathrm{V}+\mathrm{A}$ $+Z$ ) ratio, correlates with light intensity [9] and the degree of shade tolerance of a given species [8].

On 2 July 2019, Chile experienced a total solar eclipse. The umbra of this eclipse, the inner region of the shadow cast by the Moon with total occlusion of sunlight, spanned up to $147 \mathrm{~km}$. The maximum eclipse lasted for $273 \mathrm{~s}$, and the total duration of the eclipse in the umbra region was $2 \mathrm{~h}$ and $24 \mathrm{~min}$. The umbra region was located, latitudinally, on the coast of the Coquimbo Region, where Bosque Fray Jorge National Park (BFJ) is. This is a relict forest dominated by tree species belonging to the native forests of central (sclerophyllous) and southern (temperate) Chile [10]. The floristic composition shows 440 species of native plants, with 266 species endemic to Chile [10], and the vegetation includes relict elements such as Aextoxicon punctatum (common name olivillo) and Drimys winteri (common name canelo), as well as the shrub Porlieria chilensis (common name Guayacán). These species have different degrees of shade tolerance, where $D$. winteri and A. punctatum are shadetolerant, and P. chilensis is shade-intolerant $[11,12]$. In BFJ, in particular, D. winteri seems to occupy shadier sites than A. punctatum, and P. chilensis is usually found only in relatively open areas (personal observation).

The main goal of our study was to capture and quantify changes in gas exchange and responses of pigments related to the xanthophyll cycle to a total solar eclipse that occurred in Chile on 2 July 2019. To measure these effects, we evaluated three characteristic tree species of BFJ that showed different degrees of shade tolerance. Specifically, we hypothesized that: (i) rapid and progressive light limitation experienced by the solar eclipse would negatively impact the photosynthetic responses of these tree species, with greater impact in the species with lower levels of shade tolerance; and (ii) the de-epoxidation level would be related to shade tolerance during partial and total occlusion of sunlight along with this natural event (shade-tolerant: high de-epoxidation levels; shade-intolerant: low de-epoxidation levels in the xanthophyll cycle).

\section{Materials and Methods}

Study site: Bosque Fray Jorge National Park (BFJ) is located on the coast of the Coquimbo Region, Chile, just south of the Atacama Desert [10]. In the last solar eclipse in the north of Chile, BFJ was under the umbra area of the solar eclipse $(100 \%$ solar occlusion during the eclipse). The vegetation in BFJ is dominated by shrubs and succulent plants and by relict temperate tree species in some sectors influenced by sea-related moisture known as the "camanchacas" [13]. The most frequent relict BFJ forest species are A. punctatum and $D$. winteri, located in higher humidity areas [10]. In addition, $P$. chilensis is a dominant 
species of shrubland formation that plays a key role in arid ecosystems as it performs hydraulic lifts $[14,15]$. We consider these species to be representative of the BFJ, and we classify them according to their shade tolerance (defined as the minimum light requirement for plant survival) as follows: D. winteri is classified as shade-tolerant, A. punctatum as intermediate, and P. chilensis as shade-intolerant.

Experiment data collection: In the study site, we quantified the gas exchange (photosynthesis $\left(\mu \mathrm{mol} \mathrm{CO} \mathrm{Cm}^{-2} \mathrm{~s}^{-1}\right)$ and stomatal conductance $\left(\mathrm{mmol} \mathrm{H}_{2} \mathrm{O} \mathrm{m}^{-2} \mathrm{~s}^{-1}\right)$ from $08: 00 \mathrm{~h}$ am to 19:00 $\mathrm{h}$ in both control (non-eclipse) and at the eclipse day in three individuals of each studied species. On each day (non-eclipse and eclipse), we recorded gas-exchange parameters with different frequencies depending on the proximity to the time of the total eclipse. From 08:00 to 15:00 h and 17:00 to 19:00 h, we recorded these traits every $60 \mathrm{~min}$, while during the eclipse (from 15:15 to 16:45 h), we collected data every $15 \mathrm{~min}$. We conducted 23 measurements in total per individual per species in both a non-eclipse and an eclipse day. We considered the gas-exchange data of "non-eclipse day" as the average of the photosynthesis measured the previous and the next day of the eclipse. This was performed in order to discard any possible effects of a particular climatic condition of a given day. Leaf-level gas exchange was measured using an infrared gas analyzer (IRGA) (LI-6400XT portable photosynthesis system, LiCor Biosciences, Lincoln, NE, USA). To assess photosynthesis under natural solar variation, we used a leaf chamber with transparent covering (Model: 6800-12A) with a $\mathrm{CO}_{2}$ concentration set to $370 \mathrm{ppm}$. Data from leaf-level photosynthesis measurements were obtained for all the tree species in individuals ranging from 1.60 to $1.70 \mathrm{~m}$ tall, and we considered sun-exposed branches with north orientation and mature and fully expanded leaves. Each leaf selected for gas-exchange measurements was previously inspected and only those that were visually healthy and without evidence of apparent damage were used.

Additionally, we took measurements of PAR and air temperature close to the canopy (30-50 cm away from the tree) of each individual selected for gas-exchange measurements. We measured PAR using a quantum sensor (Li-250, LiCor, NE, USA) and temperature with a digital thermometer (871A, Tegam, HO, USA). We assessed the fluctuations in both variables through time by selecting the same time intervals used in the gas-exchange measurements.

On the other hand, and using the same individuals in which the gas-exchange measurements were conducted, we collected $0.1 \mathrm{~g}$ of fresh leaves in liquid nitrogen. Violaxanthin $(\mathrm{V})$, zeaxanthin (Z), and antheraxanthin (A), the pigments involved in the xanthophyll cycle, were determined following previously published methods [16]. In short, leaves were extracted in cold acetone 3 times with sonication for $45 \mathrm{~min}$ at $4{ }^{\circ} \mathrm{C}$ (ultrasonic bath Typ T570/H; Elma). The solvents used were acetonitrile/methanol $(85: 15 \mathrm{v} / \mathrm{v})$ and methanol/ethyl acetate $(68: 32 \mathrm{v} / \mathrm{v})$. The HPLC gradient used was $0-14 \mathrm{~min} 100 \% \mathrm{~A}, 14-16 \mathrm{~min}$ decreasing to $0 \%$ A, 16-28 $\min 0 \%$ A, 28-30 min increasing to 100\% A, and 30-38 min 100\% A. Detection was conducted at $445 \mathrm{~nm}$ (diode Array detector 1000S; Applied Biosystems, Foster City, CA, USA). We identified the molecules by their spectra and by coelution with authentic standards (all by Fluka, Buchs, Switzerland). The de-epoxidation state of the xanthophyll cycle was quantified following to [17] as: $(0.5 \times \mathrm{A}+\mathrm{Z}) /(\mathrm{V}+\mathrm{A}+\mathrm{Z})$.

Data analysis: To provide evidence for the impact of solar eclipse on each tree study species, we plotted the kinetics of gas-exchange measurements (Y-axis) both on a noneclipse (normal dynamics) and eclipse day (eclipse dynamics), and measurement times from 08:00 $\mathrm{h}$ am to 19:00 (X-axis) for each tree species. To compare the effect of solar eclipse on leaf-level photosynthesis, stomal conductance, and de-epoxidation state of the different tree species over time, we carried out repeated measure ANOVAs, after evaluating the normality and homogeneity of the variance of our data using the Shapiro-Wilk and Levene tests [18]. In addition, with the repeated measure ANOVAs, we compared the differential in photosynthesis between a non-eclipse and eclipse day along day, as well as the de-epoxidation state along time, for each study species on eclipse day. 


\section{Results}

All the studied tree species showed differences between control (non-eclipse day) and eclipse dynamics (eclipse day) in daily photosynthetic performance $\left(\mathrm{F}_{2,12}=5240.5\right.$; $p<0.001$, Figure 1a). Overall, all species showed a lower level of photosynthesis in the beginning and towards the end of the solar eclipse (orange zone in Figure 1) compared with individuals of the same species in a non-eclipse day; this trend was most evident at the peak of the solar eclipse $\left(\mathrm{F}_{22,264}=1324.9 ; p<0.001\right.$; red line in Figure 1$)$. Contrarily, stomatal conductance did not differ between non-eclipse and eclipse days $\left(\mathrm{F}_{2,12}=0.1 ; p=0.89\right.$; Figure 1b) but, as expected, changed significantly with the time of day $\left(F_{22,264}=1201.7\right.$; $p<0.001$, Figure 1b).

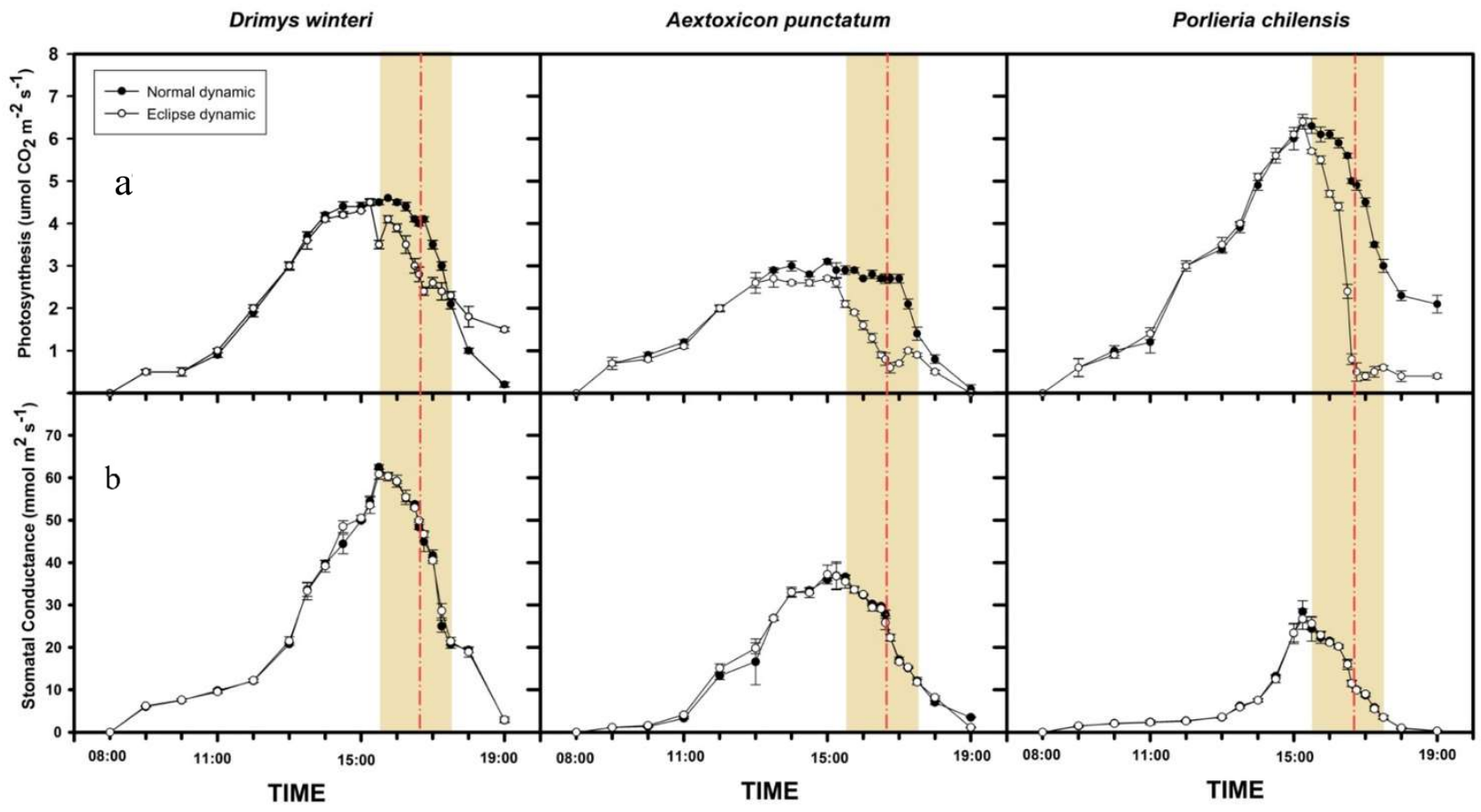

Figure 1. Daily photosynthesis(a) and stomatal conductance (b) during a control (non-eclipse) and an eclipse dayin Drimys winteri (shade-tolerant), Aextoxicon punctatum (intermediate), and Porlieria chilensis (shade-intolerant). Normal dynamics (non-eclipse day, filled circles) and eclipse dynamics (eclipse day, open circles). Shaded zones represent partial solar eclipse. The red dashed vertical line represents total solar eclipse (2 July 2019). Mean \pm 1 SD are shown.

On the day of the eclipse, all species showed lower photosynthesis differential values (eclipse photosynthesis-non-eclipse photosynthesis), particularly during the total eclipse period (Figure 2a; $F_{22,132}=172.4 ; p<0.001$ ). The species that had a significantly lower differential value was the shade-intolerant $P$. chilensis (yellow triangles, Figure $2 \mathrm{a}$ ) and the intermediate-tolerant $A$. punctatum (oranges circles, Figure 2a; $F_{2,132}=345.9 ; p<0.001$ ). Contrarily, the species that was least affected was the more shade-tolerant $D$. winteri (Figure 2a). 


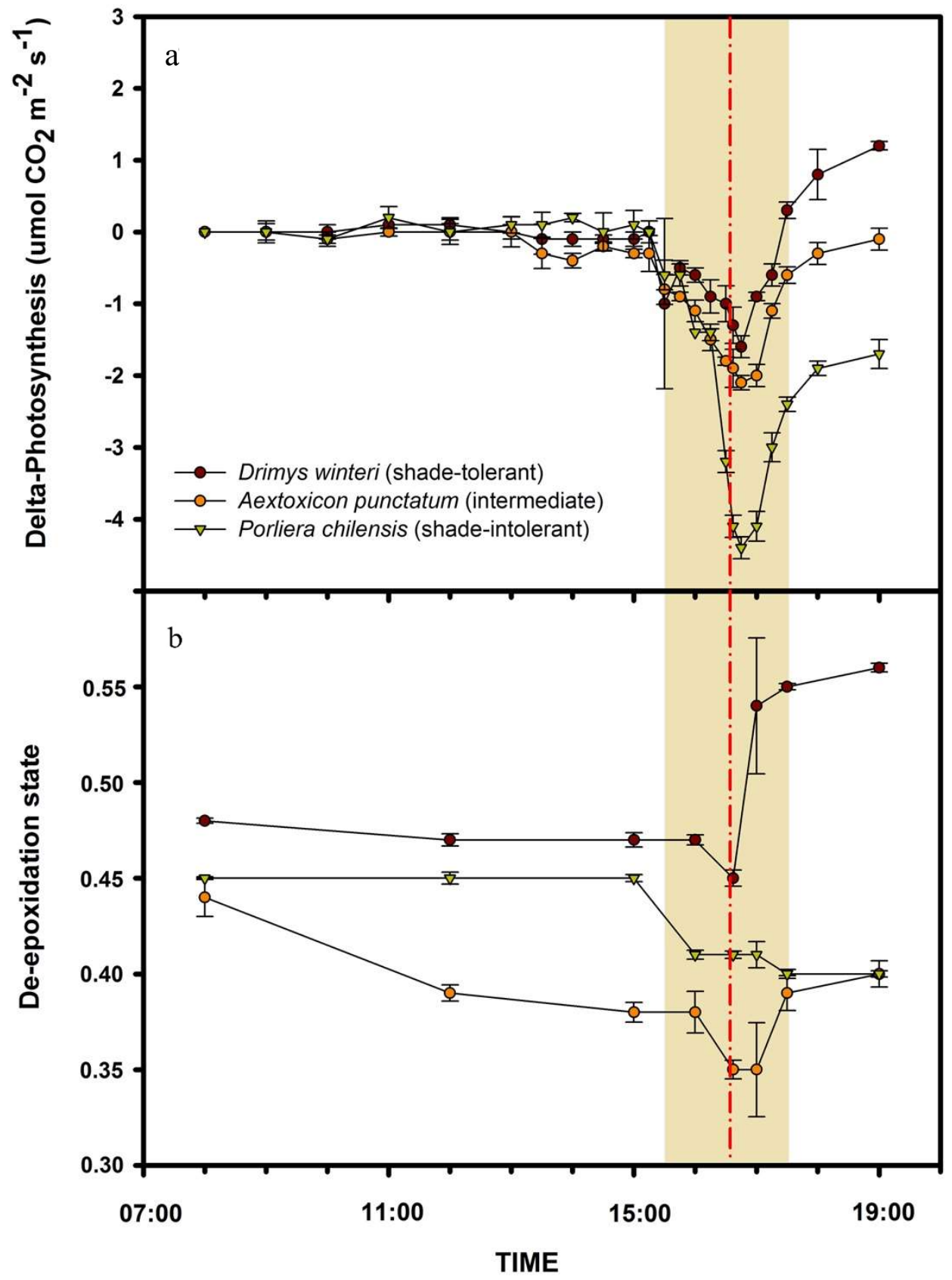

Figure 2. Daily photosynthesis differential (photosynthesis during an eclipse day-photosynthesis during a non-eclipse day) (a) and daily de-epoxidation state during an eclipse in Drimys winteri (shade-tolerant, red circles) (b), Aextoxicon punctatum (intermediate, orange circles), and Porlieria chilensis (shade-intolerant, yellow triangles). Shaded zones represent partial solar eclipse. The red dashed vertical line represents total solar eclipse (2 July 2019). Mean \pm 1 SD are shown.

Similar results were obtained for the shade-tolerance degree and de-epoxidation states, with all species showing a decrease in the de-epoxidation state values between the beginning and end of the solar eclipse (brown color in Figure $2 b ; F_{7,42}=18.8 ; p<0.001$ ). Among study species, the most significant variations were for intermediate and shadetolerant species (A. punctatum and D. winteri, respectively, Figure 2b). Moreover, in Drimys winteri, de-epoxidation was significantly higher compared to the other study species, particularly during, and right after, the total eclipse (Figure $2 b ; \mathrm{F}_{2,42}=18.8 ; p<0.001$ ). On the other hand, the shade-intolerant $P$. chilensis had the lowest de-epoxidation state during the eclipse by a significant margin (Figure $2 b$ ). 


\section{Discussion}

Our results show that light limitation experienced during the solar eclipse negatively impacted the photosynthetic responses of the tree species, with a greater impact on those species with lower levels of shade tolerance. In addition, de-epoxidation levels were related to shade tolerance; the tree species with greater shade tolerance were those that showed the highest level of de-epoxidation. Solar eclipses provide a unique opportunity to understand the effects of rapid and progressive light limitations of solar radiation on the biosphere and on trees [19]. Although the effects of a solar eclipse on plant performance have been previously reported [20], its effects on plant physiology and on plant species with varying degrees of shade tolerance remain poorly assessed.

Leaf-level measurements showed differences between a control (non-eclipse) and an eclipse day, suggesting that little and rapid variations in solar radiation could negatively impact photosynthesis (over $50 \%$ in some species) but not necessarily stomatal conductance. Photosynthesis is a key process for plants that is directly related to carbon balance and, in turn, to fitness and overall performance [21-23]. These responses may be associated with limitations in light quantity, but also with the quality of the solar eclipse light [5]. During a total eclipse, all wavelengths are reduced, but blue and UV wavelengths are reduced less than red and far-red (FR) wavelengths [24,25]. This change in light quality can potentially be sensed by phytochromes and cryptochromes and trigger rapid physiological responses. A low FR light can reduce photosynthesis since FR can activate the PSI and cyclic electron transport [26], resulting in greater ATP generation but lower NADP+ production [27], even at relatively low irradiances [28]. This could partially explain the rapid decrease (and later increase) in photosynthesis observed during the eclipse. Additionally, changes in R/FR ratios can impact the de-epoxidation state, [29] which, in turn, can affect photosynthesis during and after an eclipse. However, it must be considered that plants exposed to eclipse events can experience changes in different environmental conditions (e.g., air temperature) and not only in solar radiation (see Supplementary Material). Thus, additional studies must be conducted to assess the relative effect exerted by each environmental condition (and their interaction) that changes during an eclipse on plant physiology.

Beyond the expected reduction in photosynthesis due to reduced light, this reduction was not equal for all studied species. Of all the tested species, P. chilensi is the most shadeintolerant $[12,30]$ and, coincidentally, was the species where photosynthesis was reduced more during the eclipse (Figure 1) compared to the other, more shade-tolerant species such as D. winteri and A. punctatum $[11,31,32]$. The results in photosynthesis correlated with the de-epoxidation state of the xanthophyll cycle; the more shade-tolerant species, $D$. winteri and $A$. punctatum, had a higher de-epoxidation state compared to the shade-intolerant $P$. chilensis, particularly during the eclipse. As mentioned earlier, the de-epoxidation state is related to the degree of shade tolerance [8]. Here, the increase in the xanthophyll cycle in the shade-tolerant species during, and right after the eclipse could protect plants from photoinhibition by dissipating the excess energy as heat [33,34], and thus contribute to the lesser reduction in photosynthesis evidenced in the photosynthesis differential. Although the studied species showed a different daily dynamic of de-epoxidation state according to their shade-tolerance degree both in control and eclipse days, surprisingly, almost half of xanthophylls were in de-epoxidation form, even in the early morning. This phenomenon has been previously evidenced in other species mainly when the low night temperatures, together with the early-morning solar radiation, induce photoinhibition in some plants [see, 35 and reference therein]. In fact, in some alpine plants, zeaxanthin is retained overnight, even after extended dark periods, in order to contribute to thermal energy dissipation when plants are exposed to early morning solar radiation [35,36].

In a natural context, light quantity and quality can change daily, even at different times of the day. Shading can indicate the presence of neighbor plants that compete for light and, with time, can trigger known morphological responses such as increased $\mathrm{Chl}$ a/Chl $\mathrm{b}$ ratio, a higher leaf area, and reduced root/shoot ratios [34,37]. However, short-term shading has been less studied than its counterpart, the sunflecks (i.e., short, high-light 
periods). Sunflecks are known to impact overall carbon gain [38,39]. Thus, a total eclipse can be considered as an inverse sunfleck, where the reduction in solar light during the eclipse is responsible for the decrease in photosynthetic performance. Our results show the importance of a solar eclipse day on photosynthesis and de-epoxidation states, revealing the known high dependency of these processes on the spatial and temporal variations in light. Short and unpredicted shading could have negative consequences for the overall carbon balance of plants and likely require further study, especially in relation to how different species with different degrees of shade tolerance cope with these inverse sunflecks or sudden periods of low light.

It remains to be studied whether eclipses can exert selective pressures on plants and/or whether some of the adaptative functional responses of plants to environmental conditions such as shade and drought can result in a better performance during these astronomical events. Given the low frequency and unpredictability of eclipses, the latter is more likely to happen in most species, and more studies could contribute to determining general patterns in different plant species.

Supplementary Materials: The following are available online at https://www.mdpi.com/article/ $10.3390 / \mathrm{f} 12101353 / \mathrm{s} 1$. Figure of variation in the PAR radiation (a) and air temperature (b) along day, in an eclipse day and non-eclipse day.

Author Contributions: M.A.M.-M., C.A. designed the experiments. M.A.M.-M., F.C.-U. performed the experiments. M.A.M.-M., F.C.-U. analyzed the data. M.A.M.-M. wrote the paper along with F.C.-U., C.A. All authors have read and agreed to the published version of the manuscript.

Funding: This research received no external funding.

Data Availability Statement: The dataset can be obtained from the website: https://bioveg-lab.cl/ (accessed on 20 September 2021), upon request to the corresponding author.

Acknowledgments: We thank Paula Rodríguez, Matias Contreras, and Fabrizio Guerra for their assistance in the field with leaf photosynthesis measurements and lab assays.

Conflicts of Interest: The authors declare no conflict of interest.

\section{References}

1. Tramer, E.J. Bird Behavior during a Total Solar Eclipse. Wilson J. Ornithol. 2000, 112, 431-432. [CrossRef]

2. Rutter, S.; Tainton, V.; Champion, R.; Le Grice, P. The effect of a total solar eclipse on the grazing behaviour of dairy cattle. Appl. Anim. Behav. Sci. 2002, 79, 273-283. [CrossRef]

3. Galen, C.; Miller, Z.; Lynn, A.; Axe, M.J.; Holden, S.; Storks, L.; Ramirez, E.; Asante, E.; Heise, D.; Kephart, S.R.; et al. Pollination on the Dark Side: Acoustic Monitoring Reveals Impacts of a Total Solar Eclipse on Flight Behavior and Activity Schedule of Foraging Bees. Ann. Entomol. Soc. Am. 2019, 112, 20-26. [CrossRef]

4. Farquhar, G.D.; Sharkey, T.D. Stomatal Conductance and Photosynthesis. Annu. Rev. Plant Physiol. 1982, 33, 317-345. [CrossRef]

5. Beverly, D.; Guadagno, C.R.; Bretfeld, M.; Speckman, H.N.; Albekem, S.E.; Ewers, B.E. Hydraulic and photosynthetic responses of big sagebrush to the 2017 total solar eclipse. Sci. Rep. 2019, 9, 8839. [CrossRef]

6. Zavala, M.A.; Angulo, Ó.; De La Parra, R.B.; López-Marcos, J.C. An analytical model of stand dynamics as a function of tree growth, mortality and recruitment: The shade tolerance-stand structure hypothesis revisited. J. Theor. Biol. 2007, 244, 440-450. [CrossRef]

7. Comita, L.S.; Hubbell, S.P. Local neighborhood and species' shade tolerance influence survival in a diverse seedling bank. Ecology 2009, 90, 328-334. [CrossRef]

8. Feng, J.; Zhao, K.; He, D.; Fang, S.; Lee, T.M.; Chu, C.; He, F. Comparing shade tolerance measures of woody forest species. PeerJ 2008, 6, e5736. [CrossRef]

9. Mathur, S.; Jain, L.; Jajoo, A. Photosynthetic efficiency in sun and shade plants. Photosynthetica 2018, 56, 354-365. [CrossRef]

10. Squeo, F.A.; Loayza, A.P.; López, R.P.; Gutiérrez, J.R. Vegetation of Bosque Fray Jorge National Park and its sur-rounding matrix in the Coastal Desert of north-central Chile. J. Arid. Environ. 2016, 126, 12-22. [CrossRef]

11. Figueroa, J.A.; Lusk, C.H. Germination requirements and seedling shade tolerance are not correlated in a Chilean temperate rain forest. New Phytol. 2001, 152, 483-489. [CrossRef] [PubMed]

12. Gutiérrez-Caro, B.; Gacitúa-Arias, S.E.; Perret, S.; Sandoval, S.; Curimil, M. Propagación de Especies Forestales Nativas de las Zonas Áridas y Semiáridas de Chile; Instituto Forestal INFOR: Santiago, Chile, 2013.

13. CONAF. Catastro de Uso del Suelo y Vegetación; Corporación Nacional Forestal: Santiago, Chile, 2004. 
14. Muñoz, M.R.; Squeo, F.A.; León, M.; Tracol, Y.; Gutiérrez, J.R. Hydraulic lift in three shrub species from the Chilean coastal desert. J. Arid. Environ. 2008, 72, 624-632. [CrossRef]

15. Morales, J.; Squeo, F.A.; Tracol, Y.; Armas, C.; Gutiérrez, J.R. Resource economics and coordination among above- and belowground functional traits of three dominant shrubs from the Chilean coastal desert. J. Plant Ecol. 2015, 8, 70-78. [CrossRef]

16. Munné-Bosch, S.; Alegre, L. Changes in carotenoids, tocopherols and diterpenes during drought and recovery, and the biological significance of chlorophyll loss in Rosmarinus officinalis plants. Planta 2000, 210, 925-931. [CrossRef]

17. Molina-Montenegro, M.A.; Peñuelas, J.; Munné-Bosch, S.; Sardans, J. Higher plasticity in ecophysiological traits enhances the performance and invasion success of Taraxacum officinale (dandelion) in alpine environments. Biol. Invasions 2012, 14, 21-33. [CrossRef]

18. Zar, J.H. Biostatistical Analysis, 5th ed.; Prentice-Hall/Pearson: Upper Saddle River, NJ, USA, 2010.

19. Sambandan, K.; Devi, V.K.; Kumar, S.; Nancharaiah, M.; Dhatchanamoorthy, N. Effects of solar eclipse on pho-tosynthesis of Portulaca oleracea and Phyla nodiflora in coastal wild conditions. J. Phytol. 2012, 4, 34-40.

20. Tominaga, J.; Kawasaki, S.; Yabuta, S.; Fukuzawa, Y.; Suwa, R.; Kawamitsu, Y. Eclipse Effects on CO2 Profile within and above Sorghum Canopy. Plant Prod. Sci. 2010, 13, 338-346. [CrossRef]

21. Gupta, U.S. Improving photosynthetic efficiency and crop productivity. In Agro 's Annual Review of Plant Physiology; Purohit, S.S., Sahu, M.P., Eds.; Agro Botanical Publishers: Bikaner, India, 1994; pp. 1-50.

22. Blankenship, R.E. Molecular Mechanisms of Photosynthesis, 2nd ed.; Wiley-Blackwell: Oxford, UK, 2014.

23. Shevela, D.; Björn, L.O.; Govindjee, G. Photosynthesis: Solar Energy for Life; World Scientific Publishing: Singapore, 2019.

24. Gröbner, J.; Kröger, I.; Egli, L.; Hülsen, G.; Riechelmann, S.; Sperfeld, P. The high-resolution extraterrestrial solar spectrum (Qasumefts) determined from ground-based solar irradiance measurements. Atmos. Meas. Tech. 2017, 10, 3375-3383. [CrossRef]

25. Bernhard, G.; Petkov, B. Measurements of spectral irradiance during the solar eclipse of 21 August 2017: Reas-sessment of the effect of solar limb darkening and of changes in total ozone. Atmos. Chem. Phys. 2019, 19, 4703-4719. [CrossRef]

26. Govindjee, G.; Shevela, D.; Björn, L.O. Evolution of the Z-scheme of photosynthesis. Photosynth. Res. 2017, 133, 5-15. [CrossRef]

27. Laisk, A.; Talts, E.; Oja, V.; Eichelmann, H.; Peterson, R.B. Fast cyclic electron transport around photosystem I in leaves under far-red light: A proton-uncoupled pathway? Photosynth. Res. 2010, 103, 79-95. [CrossRef]

28. Kono, M.; Yamori, W.; Suzuki, Y.; Terashima, I. Photoprotection of PSI by far-red light against the fluctuating light-induced photoinhibition in Arabidopsis thaliana and field-grown plants. Plant Cell Physiol. 2017, 58, 35-45.

29. Wang, F.; Yan, J.; Jalal-Ahammed, G.; Wang, X.; Bu, X.; Xiang, H.; Li, Y.; Lu, J.; Liu, Y.; Qi, H.; et al. PGR5/PGRL1 and NDH Mediate Far-Red Light-Induced Photoprotection in Response to Chilling Stress in Tomato. Front. Plant Sci. 2020, $11,669$. [CrossRef]

30. Noton, C. El Guayacán. Chile Forest. 1987, 142, 16-18.

31. Lusk, C.H.; Contreras, O. Foliage area and crown nitrogen turnover in temperate rain forest juvenile trees of differing shade tolerance. J. Ecol. 1999, 87, 973-983. [CrossRef]

32. Parada, T.; Lusk, C.H. Patrones en la mortalidad de plántulas de especies arbóreas de un bosque de la transición templadomediterránea de Chile. Gayana Bot. 2011, 68, 236-243. [CrossRef]

33. Jahns, P.; Latowski, D.; Strzalka, K. Mechanism and regulation of the violaxanthin cycle: The role of antenna proh-teins and membrane lipids. Biochim. Biophys. Acta Bioenerget. 2009, 1787, 3-14. [CrossRef] [PubMed]

34. Lambers, H.; Oliveira, R.S. Plant Physiological Ecology, 3rd ed.; Springer: New York, NY, USA, 2019.

35. Körner, C. Alpine Plant Life, 3rd ed.; Springer International Publishing: Berlin/Heidelberg, Germany, 2021; 500p.

36. Streb, P.; Shang, W.; Feierabend, J.; Bligny, R. Divergent strategies of photoprotection in high-mountain plants. Planta 1998, 207, 313-324. [CrossRef]

37. Givnish, T.J. Adaptation to sun and shade: A whole-plant perspective. Aust. J. Plant Physiol. 1988, 15, 63-92. [CrossRef]

38. Pearcy, R.W. Sunflecks and photosynthesis in plant canopies. Annu. Rev. Plant Physiol. Plant Mol. Biol. 1990, 41, 421-453. [CrossRef]

39. Chazdon, R.L.; Pearcy, R.W. The Importance of Sunflecks for Forest Understory Plants. BioScience 1991, 41, 760-766. [CrossRef] 